
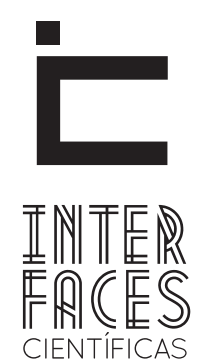

EDUCAÇÃO

ISSN IMPRESSO 2316-333X

E-ISSN 2316-3828

DOI 10.17564/2316-3828.2016v4n2p97-106

\title{
LEITURA, TEXTOS OFICIAIS E PROVINHA BRASLL: REFLEXÕES SOBRE UM MESMO TEMA
}

Solange dos Santos ${ }^{1}$

\section{RESUMO}

A par da necessidade de estudar os documentos norteadores do ensino de leitura no Brasil e a relação que estes mantêm com os recursos utilizados em sala de aula, este artigo busca observar como a Provinha Brasil segue as diretrizes relacionadas ao ensino de leitura, sugeridas nos textos oficiais concernentes às séries iniciais. Para tanto, descreve os objetivos, os pressupostos teóricos e a metodologia da Provinha Brasil e analisa as questões dos testes 1 e 2 da edição 2013. A análise ratifica a ideia de que a Provinha
Brasil concebe a leitura como prática social, que vai além da decodificação, abrangendo especificidades da alfabetização e do letramento.

\section{PALAVRAS-CHAVE}

Leitura. Textos Oficiais. Provinha Brasil. 


\section{ABSTRACT}

Knowing the need to study the guiding documents of the teaching of reading in Brazil and their relation with the resources which are used in the classroom, this article aims to observe how Provinha Brasil follows the guidelines related to the teaching of reading, which is suggested in the official texts when it comes to the initial grades. Therefore, it describes the objectives, the theoretical assumptions and the methodology of Provinha Brasil and analyzes the questions of the tests 1 and 2 of the 2013 edition.
The analysis ratifies the idea that Provinha Brasil conceives reading as a social practice, which goes beyond decoding, by encompassing specificities of alphabetization and literacy.

\section{KEYWORDS}

Reading. Official texts. Provinha Brasil.

\section{RESUMEN}

Al conocer la necesidad de estudiar los documentos que rectoran la enseñanza de la lectura en Brasil y la relación que tienen con los recursos utilizados en las clases, este artículo pretende observar cómo la Provinha Brasil sigue las directrices relacionadas con la enseñanza de la lectura, sugeridas en los textos oficiales en relación con los primeros grados. Por lo tanto, describen los objetivos, los presupuestos teóricos y la metodología de Provinha Brasil y analiza las cuestiones de los exámenes 1 y 2 edición de 2013. El análisis confirma la idea de que la Provinha Brasil ve la lectura como una práctica social que va más allá de la descodificación, incluidas las peculiaridades de la alfabetización y la lectoescritura.

\section{PALABRAS CLAVE}

Lectura. Textos oficiales. Provinha Brasil. 


\section{INTRODUÇ̄̃̃O}

A leitura é considerada uma das atividades mais importantes na escola. Nas séries iniciais, dominar o código escrito é considerado critério de avaliação para que o aluno possa prosseguir para as séries posteriores. Porém, a realidade educacional brasileira mostra que há uma grande dificuldade de desenvolver os processos envolvidos no ensino de leitura e muitos alunos acabam sendo promovidos para as séries seguintes sem saber ler e escrever.

Dados divulgados pelo Instituto Brasileiro de Geografia e Estatística (IBGE), por meio do Censo Demográfico 2010, mostraram que, na faixa etária de 10 a 14 anos de idade, a taxa de analfabetismo foi de 3,9\%, apontando que 671 mil crianças, nas idades adequadas ao ensino fundamental, não sabiam ler e escrever um bilhete simples. Esse fato reflete a necessidade de analisar as razões que provocam o insucesso na formação de leitores, principalmente, nas séries iniciais, que é a base do ensino.

Para identificar os problemas que dificultam o desenvolvimento das habilidades dos alunos, são aplicadas avaliações diagnósticas como a Provinha Brasil, que oferece um diagnóstico do nível de alfabetização e letramento nos anos iniciais do ensino fundamental, indicando as principais dificuldades no que se refere às capacidades de leitura.

A par dessa perspectiva, este artigo, recorte da dissertação intitulada Leitura e Provinha Brasil: dos pressupostos teóricos ao diagnóstico de habilidades, resultante de atividades ligadas ao projeto Ler+Sergipe - leitura para o letramento e cidadania, vinculado ao Programa Observatório da Educação (edital 38/2010/CAPES/INEP), busca refletir sobre 0 ensino de leitura nas séries iniciais, discutindo sobre as concepções veiculadas nos textos oficiais e na Provinha Brasil.
Nesse sentido, a proposta metodológica consiste em observar como a Provinha Brasil segue as orientações, voltadas para o ensino de leitura, sugeridas nos textos oficiais concernentes às séries iniciais. Para cumprir tal intento, abordamos as concepções de leitura veiculadas nos documentos oficiais. Em seguida, descrevemos as características da Provinha Brasil a partir da leitura do kit (material impresso da avaliação) da edição 2013 e analisamos as questões dos testes 1 e 2 da mesma edição, ressaltando as habilidades trabalhadas.

\section{DIRETRIZES PARA O ENSINO DE LEITURA NAS SÉRIES INICIAIS}

O Ministério da Educação da Cultura (MEC) publicou diretrizes, parâmetros, referenciais curriculares, planos, projetos, entre outros materiais, com o propósito de nortear o trabalho docente, orientando as atividades didáticas em sala de aula. Selecionamos os Parâmetros Curriculares Nacionais (PCN), referentes às quatro primeiras séries da educação fundamental, os Parâmetros em ação, o Referencial Curricular Nacional para a Educação Infantil e o material do Pró-Letramento - Programa de Formação Continuada de Professores dos Anos/Séries Iniciais, a fim de observar de que maneira o ensino de leitura é tratado em textos norteadores.

Em 1997, o MEC publicou os PCN de $1^{\mathrm{a}}$ a $4^{\mathrm{a}}$ séries. No geral, este documento consiste em uma proposta para a educação brasileira, com o propósito de orientar a formulação dos currículos escolares, apresentando os objetivos de cada disciplina.

O Referencial Curricular Nacional para a Educação Infantil, publicado em 1998, tem como finalidade contribuir para o planejamento, o desenvolvimento e a avaliação das práticas educativas da primeira etapa 
da educação básica. Objetivando a formação continuada de professores, os Parâmetros em ação, lançados em 1999, possibilitam o aprofundamento dos conhecimentos sobre os Referenciais Curriculares, esclarecendo até muitas dúvidas a respeito dos PCN. Outro material voltado para formação continuada é o do Pró-Letramento, divulgado em 2007, ${ }^{1}$ abordando questões ligadas à alfabetização e ao letramento.

Nos PCN, já é apresentada, na introdução da caracterização da língua portuguesa, a visão de que "no Ensino Fundamental, o eixo da discussão, no que se refere ao fracasso escolar, tem sido a questão da leitura e da escrita" (BRASIL, 1997, p. 19). Os índices de repetência na primeira e quinta séries (atual $2^{\circ}$ e $6^{\circ}$ anos) são atribuídos à dificuldade da escola em ensinar a ler e escrever: i) na primeira série, por problemas no ensino de alfabetização; ii) na quinta série, por não desenvolver o uso eficaz da linguagem.

Para observar como as concepções de leitura são apresentadas, é preciso, inicialmente, buscar a concepção de língua e texto concebida nos materiais. Segundo os PCN, "a língua é um sistema de signos histórico e social que possibilita ao homem significar o mundo e a realidade" (BRASIL, 1997, p. 22). A concepção de língua dos Parâmetros em Ação, assim como nos PCN, é a que se realiza no uso, nas práticas sociais. Neste contexto, a atividade de leitura é vista como um processo que envolve a língua em uso, e não apenas um processo de decodificação. Percepção semelhante é notada no Referencial Curricular Nacional para a Educação Infantil e nos fascículos do Pró-letramento. "A língua é um sistema que tem como centro a interação verbal, que se faz através de textos ou discursos, falados ou escritos" (BRASIL, 2008. p. 9).

0 conceito de texto pertinente a esses documentos pode ser exemplificado como "o produto da atividade discursiva oral ou escrita que forma um todo significativo e acabado, qualquer que seja sua exten-

1. Optamos pela leitura do material publicado em 2008 por ser uma edição revisada e ampliada. são" (BRASIL, 1997, p. 23). Por ter essa compreensão de texto, enfatiza-se a importância de se trabalhar com uma diversidade de textos autênticos e critica-se a utilização dos textos elaborados nas cartilhas com o intuito de trabalhar a decodificação apenas. Nesse sentido, a concepção de leitura é de uma atividade constituída de contexto social, que envolve não só a decifração do código escrito, mas também a compreensão e a produção de sentido, abrangendo as capacidades relativas à alfabetização e ao letramento.

E falando sobre alfabetização e letramento, é de suma importância verificar de que maneira esses processos são abordados. Nos PCN, nota-se uma exploração maior do termo alfabetização em comparação ao termo letramento, que é mencionado poucas vezes. No geral, nos PCN, “a alfabetização, considerada em seu sentido restrito de aquisição da escrita alfabética, ocorre dentro de um processo mais amplo de aprendizagem da Língua Portuguesa” (BRASIL, 1997, p. 28). Esse processo mais amplo de aprendizagem, em algumas partes dos parâmetros, foi interpretado como um processo que inclui práticas de letramento, que "[...] é entendido como produto da participação em práticas sociais que usam a escrita" (BRASIL, 1997, p. 28).

0 texto do Pró-letramento traz uma explicação histórica sobre os termos, afirmando que o termo alfabetização passou a ser utilizado para se referir ao aprendizado inicial do funcionamento do sistema de escrita, enquanto o termo letramento aos usos da língua escrita. Nessa concepção, "são processos diferentes, cada um com suas especificidades, mas complementares e inseparáveis, ambos indispensáveis" (BRASIL, 2008, p. 13).

Nesse sentido, acredita-se que a ação pedagógica mais apropriada para as séries iniciais é aquela que relaciona a alfabetização e o letramento, garantindo a aquisição do sistema alfabético e a aplicação da língua nas práticas sociais de leitura e escrita, em outras palavras, "alfabetizar letrando" (BRASIL, 2008, p. 13). 
Outro ponto que merece destaque é a perspectiva teórica que embasa esses materiais. Os PCN enfatizam que, no início de 1980, a psicogênese da língua escrita, também conhecida como construtivismo, influenciou muitos trabalhos transformando o modo de compreender o processo de alfabetização. No material do Pró-letramento, o construtivismo também é abordado, elucidando que "[...] algumas compreensões equivocadas dessas teorias têm acarretado outras formas de reducionismo" (BRASIL, 2008, p. 12).

Um ponto mal interpretado foi o entendimento de que práticas como a decodificação e os métodos fônicos não favoreciam em nada o processo inicial da alfabetização. Dentro da percepção construtivista apresentada nos PCN, a decodificação deixa de ser pré-requisito para o início do ensino de língua, ou seja, não é necessário inicialmente trabalhar com práticas de decodificação para somente depois iniciar práticas de letramento, mas não quer dizer que a atividade de decodificação seja desnecessária para a aquisição da escrita alfabética, como pode ser verificado no trecho a seguir:

\begin{abstract}
A compreensão atual da relação entre a aquisição das capacidades de redigir e grafar rompe com a crença arraigada de que o domínio do bê-á-bá seja pré-requisito para o início do ensino de língua e nos mostra que esses dois processos de aprendizagem podem e devem ocorrer de forma simultânea. Um diz respeito à aprendizagem de um conhecimento de natureza notacional: a escrita alfabética; o outro se refere à aprendizagem da linguagem que se usa para escrever. (BRASIL, 1997, p. 27).
\end{abstract}

No que se refere à apropriação do sistema de escrita, o material do Pró-letramento traz uma seção dedicada aos conhecimentos que os alunos necessitam para desenvolver a leitura e a escrita. Destacam-se os seguintes conhecimentos: (i) compreender diferenças entre a escrita e outras formas gráficas; (ii) reconhecer unidades fonológicas como sílabas, rimas, terminações de palavras etc.; (iii) conhecer o alfabeto; (iv) conhecer e utilizar diferentes tipos de letra (de fôrma e cursiva); (v) compreender a correspondência grafema-fonema.
Nas sugestões de atividades apresentadas no anexo no fascículo 2 do Pró-letramento, Alfabetização e Letramento: Questões sobre Avaliação, podem-se destacar dentre as habilidades solicitadas: (i) distinguir as letras de outros desenhos e sinais gráficos; (ii) reconhecer palavras de formação silábica canônica escritas de diferentes formas; (iii) ler palavras compostas por sílabas canônicas e não canônicas; (iv) ler frases e textos curtos; (v) localizar informação em textos; (vi) identificar o assunto de um texto; (vii) identificar a finalidade de textos de gêneros diversos; (viii) fazer inferências simples.

No que diz respeito à compreensão de textos, enfatiza-se que esta é a principal meta no ensino de leitura, sendo a decifração e o reconhecimento procedimentos importantes para se chegar a essa meta. Argumenta-se que a compreensão linear, a produção de inferências e a compreensão global são elementos básicos para ler com compreensão.

A compreensão linear do texto consiste na habilidade de identificar informações explícitas no corpo do texto. A produção de inferências se refere à ideia de "ler nas entrelinhas", compreender os subentendidos, compreender informações implícitas. E a compreensão global do texto será possibilitada pela identificação das informações explícitas e implícitas dos textos.

Outra questão que merece ser elucidada é a avaliação. Dentre os materiais observados, o Pró-letramento é o que traz mais detalhes sobre esta questão. Como critério de avaliação de língua portuguesa para o primeiro ciclo, espera-se que os alunos demostrem não apenas localizar informações específicas do texto, mas que compreendam o sentido global de textos lidos.

As avaliações são vistas como um instrumento fundamental para a compreensão do desenvolvimento e aprendizagem dos alunos. Elas envolvem resultados quantitativos e qualitativos. Na nossa tradição pedagógica, as avaliações com resultados 
quantitativos determinam a aprovação ou reprovação dos alunos. Mas, também há avaliações de cunho diagnóstico que apresentam resultados qualitativos que possibilitam uma descrição dos níveis de aprendizados dos alunos, bem como suas dificuldades, indicando as possíveis estratégias para o desenvolvimento das habilidades.

No segundo fascículo do material do Pró-letramento, há a seguinte afirmação: "[...] a avaliação diagnóstica pode ser utilizada tanto no início de um ano letivo, quando se inicia determinada série ou fase de um ciclo, como ao final de um ano, série ou ciclo" (BRASIL, 2008, p. 9). Nesse âmbito, pode-se ver a Provinha Brasil como uma ferramenta pedagógica de avaliação e acompanhamento do processo de alfabetização. Por isso, acredita-se que seja produtivo observar esta avaliação de caráter nacional, destacando como ela avalia as habilidades de leitura.

\section{A PROVINHA BRASIL}

A Avaliação da Alfabetização Infantil (Provinha Brasil), implementada em 2008, pelo Instituto Nacional de Estudos e Pesquisas Educacionais Anísio Teixeira (Inep), é um instrumento que oferece um diagnóstico do nível de alfabetização e letramento no início do processo de aprendizagem, após um ano no ensino fundamental. A sua finalidade não é classificatória, mas oferecer aos professores e gestores das escolas um instrumento de análise das habilidades dos alunos. Sendo assim, não há o retorno dos resultados para o MEC ou Inep, ou seja, os resultados da Provinha Brasil não são utilizados na composição do Índice de Desenvolvimento da Educação Básica (DEB), a sua aplicação é opcional, ficando a critério de cada secretaria de educação dos estados e municípios.

As secretarias de educação recebem o Kit da Provinha Brasil composto por três documentos: Guia de Aplicação; Caderno do Aluno; Guia de Correção e Interpretação de Resultados. Estes documentos consistem em cadernos que abordam a metodologia da prova, seus objetivos, pressupostos teóricos, além das orientações para a aplicação, correção e uso dos resultados.

Composta por vinte uma questões - de múltipla escolha, com quatro alternativas cada - sendo a primeira uma questão-exemplo, a Provinha Brasil exige do aluno diferentes níveis de alfabetização e letramento. As questões são corrigidas por meio da marcação das respostas certas dos alunos em uma ficha de correção que vem anexada ao Guia de Correção e interpretação dos resultados. Depois é somada a quantidade de acertos de cada aluno e calculada a média da turma.

Os desempenhos dos alunos são analisados de acordo com cinco níveis de acerto. Para chegar a esses níveis, foi realizada uma análise das dificuldades das habilidades segundo critérios estatísticos e pedagógicos, por meio de um pré-teste, realizado pelo Inep e aplicado a diferentes grupos de alunos de todo país. A partir disso, definiu-se o número de acertos para cada nível de alfabetização e letramento, de acordo com o número de questões de múltipla escolha respondidas corretamente. Na edição 2013 , foram adotados os seguintes números de acertos para cada nível de desempenho:

Figura 1 - Indicadores de nível de alfabetização e letramento da Provinha Brasil (2013)

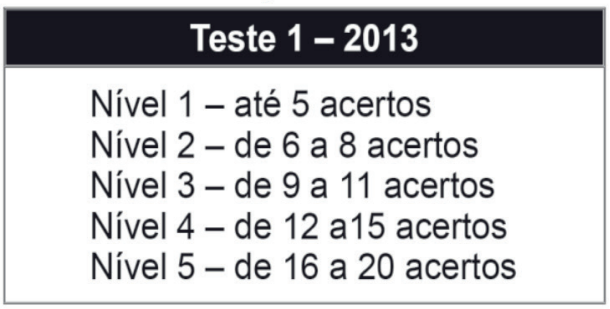

Fonte: Brasil (2013c, p. 26).

Acredita-se que as respostas dos alunos podem ser interpretadas, fazendo uma relação entre o número ou a média de acertos e os correspondentes níveis de desempenho descritos pela Provinha Brasil. Para cada nível há um conjunto de habilidades. "É impor- 
tante esclarecer que cada um desses níveis apresenta novas habilidades e engloba as anteriores, por exemplo: um aluno que alcançou o nível 3 já desenvolveu as habilidades dos níveis 1 e 2" (BRASIL, 2013c, p. 26). Eis a descrição das habilidades dos níveis de desempenho no quadro abaixo:

Quadro 1 - Descrição das habilidades dos níveis de desempenho

\begin{tabular}{|c|c|}
\hline NÍVEIS & HABILIDADES \\
\hline Nível 1 (até 5 acertos) & $\begin{array}{l}\text { identificar o valor sonoro das partes iniciais e/ou finais de palavras (al- } \\
\text { gumas letras ou sílabas) para "adivinhar" e "ler" o restante da palavra; } \\
\text { reconhecer algumas letras do alfabeto e iniciar a distinção das letras de } \\
\text { desenhos e outros sinais gráficos. }\end{array}$ \\
\hline Nível 2 (de 6 a 8 acertos) & $\begin{array}{l}\text { estabelecer relação entre letras (grafemas) e sons (fonemas); ler pa- } \\
\text { lavras compostas por sílabas formadas por consoante e vogal (sílabas } \\
\text { canônicas - CV); ler algumas palavras compostas por sílabas formadas } \\
\text { por consoante/vogal/consoante ou por consoante/consoante/vogal (sí- } \\
\text { labas não canônicas); e reconhecer palavras de formação silábica canô- } \\
\text { nica escritas de diferentes formas. }\end{array}$ \\
\hline Nível 3 (de 9 a 11 acertos) & $\begin{array}{l}\text { ler palavras compostas por sílabas canônicas e não canônicas (VC, VVC, } \\
\text { CCV, CCVC,CCVCC); identificar o número de sílabas de palavras; ler fra- } \\
\text { ses de sintaxe simples baseadas em imagens ou ditadas pelo aplicador; } \\
\text { localizar informações, por meio da leitura silenciosa, em uma frase ou } \\
\text { em textos de aproximadamente cinco linhas. }\end{array}$ \\
\hline Nível 4 (de 12 a 15 certos) & $\begin{array}{l}\text { localizar informação em textos curtos ou médios; identificar a finalida- } \\
\text { de de textos de gêneros diversos, como bilhete, sumário, convite, carta- } \\
\text { zes, livro de receita; identificar o assunto de um texto médio a partir de } \\
\text { leitura individual; e fazer inferências simples. }\end{array}$ \\
\hline Nível 5 (de 16 a 20 acertos) & $\begin{array}{l}\text { Para além das habilidades dos outros quatro níveis, demonstram, por } \\
\text { exemplo: compreender textos de diferentes gêneros e de complexida- } \\
\text { de diversa, identificando o assunto principal e localizando informações } \\
\text { não evidentes, além de fazerem inferências. }\end{array}$ \\
\hline
\end{tabular}

Fonte: Brasil (2013c).

De acordo com Guia de Correção e Interpretação de Resultados, as competências e habilidades descritas seguem a Matriz de Referência para Avaliação da Alfabetização e do Letramento Inicial, que tem como base o documento Pró-Letramento e outros documentos que norteiam as avaliações nacionais desenvolvidas pelo Inep.

Como se pode verificar no Quadro 1, destaca-se a concepção de que a leitura contempla não somente 
a atividade de decifração, mas também a de compreensão e produção de sentido, ou seja, as práticas de letramento. Dentro dessa perspectiva, ressaltam-se as habilidades de: “ler palavras e frases, localizar informações explícitas em frases ou textos, reconhecer assunto de um texto, reconhecer finalidades dos textos, realizar inferências e estabelecer relação entre partes do texto" (BRASIL, 2013c, p. 11). Para observar como na prática essas habilidades são avaliadas, torna-se relevante analisar as questões que compõem os testes.

\section{AS QUESTÕES DA PROVINHA BRASIL E OS NÍVEIS DE ALFABETIZAÇ̃̃̃O E LETRAMENTO}

Para observar como os níveis de alfabetização e letramento revelam as dificuldades dos alunos, procedeu-se à análise dos tipos de questões que constituem os testes da edição 2013. As questões foram classificadas de acordo com os níveis propostos pela Provinha Brasil, revelando as habilidades requeridas nos testes. Os resultados foram resumidos no gráfico a seguir:

Gráfico 1 - Classificação das questões segundo os níveis de desempenho da Provinha Brasil

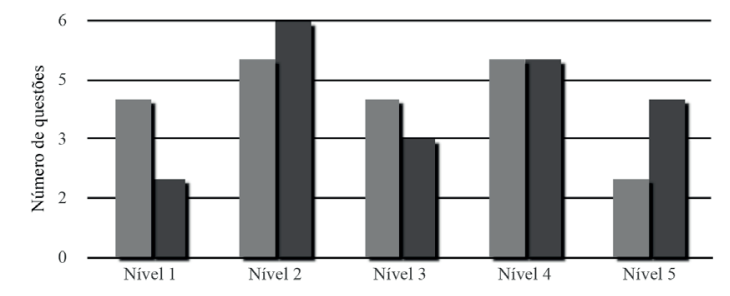

Fonte: Dados pesquisa

Comparando-se o Teste 1 ao Teste 2, percebe-se que o primeiro mostra um certo equilíbrio na distribuição das habilidades solicitadas, com exceção às questões de nível 5, o que pode ser justificado por se tratar da avaliação de entrada, que tem por objetivo analisar as habilidades desenvolvidas no $1^{\circ}$ ano, sendo assim, é provável que os alunos não tenham desenvolvido habilidades mais complexas. No Teste 2, a mudança de foco revela que se espera que os alunos tenham desenvolvido tais habilidades, por isso o acréscimo de questões correspondentes ao nível 5.

Constata-se que as questões de nível 1 solicitam as habilidades de: reconhecer o valor sonoro da sílaba inicial, de identificar as letras do alfabeto e de diferenciar letras de outros sinais gráficos. Quando se trata de questões de nível 2, as habilidades solicitadas são: relacionar grafema e fonema; identificar a relação entre significante e significado; reconhecer as palavras escritas de diferentes formas; e ler sílabas canônicas.

As questões correspondentes ao nível 3 requerem as habilidades de: identificar o número de sílabas; localizar informação explícita em um texto; ler frases com apoio da leitura do professor/aplicador; ler palavras composta por sílabas não canônicas; e ler frases com apoio de imagem. As questões de nível 4 pedem para que os alunos: identifiquem a finalidade de textos; localizem informações explícitas em um texto curto; e identifiquem o assunto de textos a partir da leitura individual.

As questões correspondentes ao nível 5 solicitam as habilidades de: estabelecer a relação entre partes do texto; inferir informação a partir de um texto; reconhecer a finalidade de um gênero textual; inferir informações no texto; e identificar substituições e/ou repetições pronominais.

A partir da comparação entre os tipos de questões e o desempenho dos alunos, o professor pode observar as habilidades que os alunos já dominam e as que necessitam ser desenvolvidas. A identificação das dificuldades no teste de entrada, no início do $2^{\circ}$ ano, ajudará ao professor no planejamento de suas aulas, direcionando o ensino para as habilidades que precisam de mais atenção. Os resultados do segundo teste possibilitam ao professor verificar se ocorreu desenvolvimento das habilidades no decorrer do ano letivo. 


\section{CONSIDERACÕES FINAIS}

0 foco deste artigo centrou-se numa reflexão sobre o ensino de leitura nas séries iniciais, trazendo à tona as concepções veiculadas nos documentos oficiais e na Provinha Brasil. Após análise dos principais elementos que compõem essa avaliação, foi possível ressaltar como de fato as habilidades de leitura são avaliadas.

Grosso modo, pode-se reconhecer na Provinha Brasil as concepções de leitura baseadas nos textos oficiais voltados para as séries iniciais do ensino fundamental, no que concerne à ideia de leitura como prática social, que não envolve somente a decodificação, mas também a compreensão e a produção de sentido, abrangendo, portanto, especificidades da alfabetização e do letramento.

Verifica-se, também, que a Provinha Brasil é composta por dois eixos, um destinado às habilidades de apropriação do sistema de escrita e outro voltado para a leitura. Dentro dessa perspectiva, é evidenciada a noção de que alfabetização e letramento são processos diferentes, mas complementares.

Outra semelhança observada entre os textos oficiais e a Provinha Brasil diz respeito às habilidades e conhecimentos assinalados no projeto Pró-letramento. Nas seções destinadas aos conhecimentos que os alunos precisam desenvolver e às sugestões de atividades, destacam-se as seguintes habilidades em comum: compreender diferenças entre escrita e outras formas gráficas; reconhecer unidades fonológicas como sílabas, rimas, terminações de palavras etc.; conhecer o alfabeto; conhecer e utilizar diferentes tipos de letra (de fôrma e cursiva); compreender a correspondência grafema-fonema; ler palavras compostas por sílabas canônicas e não canônicas; ler frases e textos curtos; localizar informação em textos; identificar o assunto de um texto; identificar a finalidade de gêneros textuais; e fazer inferências simples.
Isso corrobora a afirmação de que a Matriz de Referência para Avaliação da Alfabetização e do Letramento Inicial, utilizada pela Provinha Brasil, foi elaborada com base no documento do Pró-letramento. Não só as habilidades avaliadas permitem essa afirmação, como também as características de avaliação diagnóstica, ao aplicar um teste de entrada no início do $2^{\circ}$ ano, visando identificar as habilidades que os alunos já dominam e as que necessitam ser desenvolvidas no decorrer do ano letivo, e outro no final do ano, para verificar se tais habilidades foram desenvolvidas.

Vale ressaltar que apenas o fato de ser baseada em um documento oficial que orienta as práticas de ensino não garante a eficácia da Provinha Brasil enquanto instrumento de avaliação. Para que a Provinha Brasil desempenhe efetivamente a função de instrumento identificador das dificuldades dos alunos, é necessário que os alfabetizadores entendam todo o processo da prova, desde os objetivos à correção e interpretação dos resultados. Deve-se ter em mente que o foco não é avaliar a prática docente a partir dos resultados obtidos pelos alunos, mas contribuir para o processo de ensino-aprendizagem.

\section{REFERÊNCIAS}

BRASIL. Parâmetros Curriculares Nacionais: língua portuguesa. Brasília: MEC, 1997.

BRASIL. Programa de desenvolvimento profissional continuado - Parâmetros em ação. Primeiro e

Segundo Ciclos do Ensino Fundamental (1 $1^{\mathrm{a}}$ a $4^{\mathrm{a}}$

Série). Brasília: Ministério da Educação, Secretaria de Educação Fundamental,1999.

BRASIL. Referencial curricular nacional para a educação infantil - Conhecimento de mundo. Brasília: MEC/SEF, 1998.

BRASIL. Pró-Letramento: Programa de Formação Continuada de Professores dos Anos/Séries Iniciais 
do Ensino Fundamental: alfabetização e linguagem. ed. rev. e ampl. Secretaria de Educação Básica. Brasília: Ministério da Educação, Secretaria de Educação Básica, 2008.

BRASIL. Ministério da Educação. Instituto Nacional de Estudos e Pesquisas Educacionais Anísio Teixeira. Provinha Brasil: Caderno do Aluno. Brasília, 2013a.

BRASIL. Ministério da Educação. Instituto Nacional de Estudos e Pesquisas Educacionais Anísio Teixeira. Provinha Brasil: Guia de Aplicação. Brasília, 2013b.

BRASIL. Ministério da Educação. Instituto Nacional de Estudos e Pesquisas Educacionais Anísio Teixeira.
Provinha Brasil: Guia de Correção e Interpretação de Resultados. Brasília, 2013c.

IBGE - INSTITUTO BRASILEIRO DE GEOGRAFIA E ESTATÍSTICA. Censo Demográfico (2010). Disponível em: <http://www.ibge.gov.br/english/estatistica/ populacao/censo2010/caracteristicas_da_populacao/ resultados_do_universo.pdf> Acesso em: 24 jul. 2013

\section{IBGE - INSTITUTO BRASILEIRO DE GEOGRAFIA E ESTATÍSTICA. Indicadores Sociais Municipais:} Uma análise dos resultados do universo do Censo Demográco 2010. Disponível em: <http://www.ibge. gov.br/home/estatistica/populacao/censo2010/ indicadores_sociais_municipais/indicadores_ sociais_municipais.pdf>Acesso em: 24 jul. 2013

\begin{abstract}
1. Mestra em Letras, Universidade Federal de Sergipe (UFS), com área de concentração em Estudos Linguísticos; Tutora a distância no Centro de Educação a distância (CESAD) da Universidade Federal de Sergipe (UFS). E-mail: Rede - PROFLETRAS da Universidade Federal de Sergipe. E-mail: leilane3108@gmail.com

2. Doutora em Letras (UFPB, 2005), com área de concentração em Linguística e Língua Portuguesa; Professora do Departamento de Letras Vernáculas, do Programa de Pós-graduação em Letras - PPGL e do Mestrado Profissional de Letras em Rede - PROFLETRAS, Universidade Federal de Sergipe (UFS). E-mail: Rede - PROFLETRAS da Universidade Federal de Sergipe. E-mail: leilane3108@gmail.com
\end{abstract}

